American Journal of Agricultural and Biological Sciences 3 (2): 468-475, 2008

ISSN 1557-4989

(C) 2008 Science Publications

\title{
Sugarcane Phenological Date Estimation Using Broad-Band Digital Cameras
}

\author{
${ }^{1}$ Mobasheri, ${ }^{2} \mathrm{M}$. Chahardoli, ${ }^{3} \mathrm{~J}$. Jokar and ${ }^{4} \mathrm{M}$. Farajzadeh \\ ${ }^{1}$ Department of Remote Sensing, KNToosi University of Technology, Mirdamad Cross, \\ Valiasr Ave. P.O. Box 15875-4416, Post Code 1996715433, Tehran, Iran \\ ${ }^{2}$ Islamic Azad University, Malayer Branch and Remote Sensing and GIS Department, \\ Tarbiat Modares University, Tehran, Iran \\ ${ }^{3}$ Iran Space Agency, Tehran, Iran and Remote Sensing and GIS Department, \\ Tarbiat Modares University, Tehran, Iran \\ ${ }^{4}$ Remote Sensing and GIS Department, Tarbiat Modares University, Tehran, Iran
}

\begin{abstract}
In the agricultural industry, precision farming is the most important task that attracts lots of attentions. The health of the plant depends mostly on the amount of water in its access that can be estimated through vegetation indices. These indices can be extracted from satellite images through Image processing algorithms. The objective of this research was to provide an equation for assessment of the quality of the phenological dates of the sugarcane in Degree-Day (DD) which are usually derived using satellite data. Then these calibration equations can be used in the collection of some ground truth data applicable in remote sensing where ever the need arises. A simple way for implementing this task is to develop an algorithm (an equation) with which we can (to a limited extent) quantify the interaction of light (in the RGB region of spectrum) with the plant foliage to have DDs as their outputs. To do this 63 digital photographs were taken in three field campaigns on Sep29, 2006 through Oct1, 2006 from Amirkabir and Dea 'bal-Khazaie sugarcane sites located in the south-west of Iran. These photographs included 9 different stages of the sugarcane growth and bare soil. It was found that on the average, the effect of dust on the leaves is an increase in DN values of about 9, 8 and 13 for bands red, green and blue respectively. To find an algorithm for determination of plant phenological date four different methods were used. These were Rectangular Method (RM), Maximum Likelihood Method (MLM), Thresholding Method (TM) and Hybrid Method (HM). To test the ability of different methods in the prediction of plants DDs, three photographs with known DDs and vegetation cover percentage were used. Entering these predicted DDs and true values in the Wilcoxon signed-rank test, the degree of significance level of the predicted value of each method was evaluated. As a result MLM with $\mathrm{R}^{2}$ of 0.987 and TM method with $\mathrm{R}^{2}$ of 0.989 both with significance level of 0.827 were the best methods for estimation of phenological date using broadband digital cameras.
\end{abstract}

Keywords: Vegetation, Dust Effects, Digital Camera, Remote Sensing

\section{INTRODUCTION}

In this competitive world, the cost and efficiency has the most priority in every business ${ }^{[1]}$. In the agricultural industry, precision farming is the most important technique that attracts lots of attentions. A health monitoring program capable of accurately assessing the extent and severity of symptoms of canopy stress using digital cameras, could enable managers to take a proactive course of action to minimize losses in productivity and plant mortality ${ }^{[2]}$.

The health of the plant is mostly dependant on the amount of water in its access that can be estimated through vegetation indices ${ }^{[3]}$. On the other hand the vastness of the agricultural fields makes human supervisions difficult and expensive. This will make application of remote sensing in close monitoring vegetation condition, a necessity ${ }^{[4]}$. On the other hand the remote sensing techniques always suffer from the contamination present in the atmosphere as well as on the surfaces.

Many attempts have so far been implemented in reducing the contaminant effects of atmospheric dust and aerosols from images produced by space-borne and

Corresponding Author: Mohammad Reza Mobasheri, Department of Remote Sensing Engineering, K.N. Toosi University of Technology P.O. Box 15875-4416 Tehran, Iran Tel: +98 9121226630 Fax: +98 2188786213 
air-borne sensors ${ }^{[5,6,7,8,9,10]}$. Almost in none of these works, attention has been given to the correction of the effects of the dust covered on the leaves and foliage of the canopies when retrieving vegetation indices. The presence of these dust particles on the leaves in the regions surrounded by deserts is more profound. These dust particles, depending on their compositions, may affect the greenish of the vegetation and consequently can lower the values of indices such as NDVI, VI, SR, NDWI and many more ${ }^{[3]}$. This would add to the uncertainties related with the effect of atmospheric dust and aerosols in the retrieval of the surface parameters.

In a field study of the water stress and phenology of sugarcane canopies in the south-west of Iran using ASTER images ${ }^{[1]}$, it was noticed that the effect of the presence of a layer of ground dust on the sugarcane broad leaves are serious sources of uncertainty in the retrieval of vegetation indices from satellite images. To quantify the effect of these dusts, a broad-band digital camera was used. During this study it was found that one might be able to define a calibration equation using digital photographs. These equations can be used in collecting in-situ vegetation field information (ground truth) required for satellite data quality improvement and can be replaced traditional costly field campaigns. The detail of each method is presented in the following sections.

\section{MATERIALS AND METHODS}

The region of study is a part of Amirkabir Sugarcane Industry some 25 kilometer south of Ahvaz in Khuzestan province. The location of the field in the UTM system is in zone 39, form $237361 \mathrm{~m}$ to $239506 \mathrm{~m}$ length and from $3427183 \mathrm{~m}$ to $3428158 \mathrm{~m}$ width and is shown in Fig. (1).

The data, hardwares and softwares used in this research were:

- Digital Photographs taken by CANON-A510 camera from sugarcane fields with different Physiological Dates (PD).

- Digital Photographs taken by CANON-A510 camera from dusty and dustless leaves.

- Environmental and weather parameters such as temperature and visibility from nearest stations.

- Image processing softwares such as ERDAS IMAGINE 8.7, PCI GEOMATICA 9.1, ENVI 4.2.

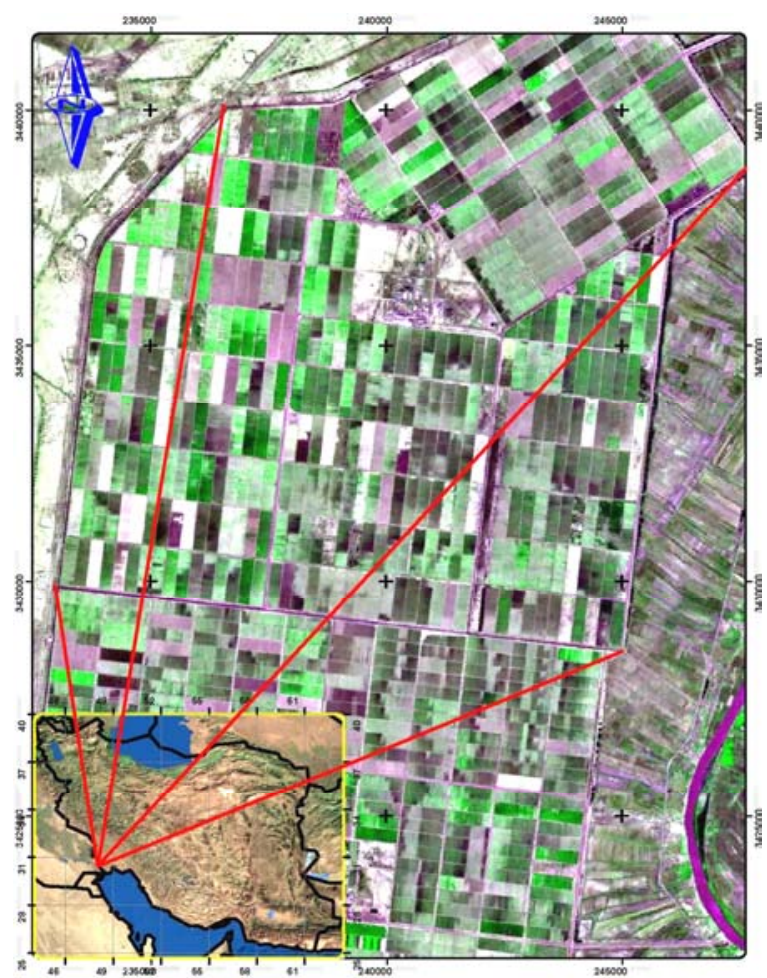

Fig. 1: location of the study region ${ }^{[1]}$.

As mentioned before, the objective of this research is the use of a digital camera for supplying an equation for assessment of the plant Physiological Dates in units of Degree Day (DD).

One of the revenues in reconnaissance of the nature of the plant is the study of its phenology. A simple way for implementing this task (supplying an equation) is to prepare an algorithm through interaction of light with the plant in the visible region of the spectrum using a digital camera. 63 digital photographs were taken in three campaigns on Sep29, 2006 through Oct1, 2006 from Amirkabir and Dea bal-Khazaie sugarcane sites. These photographs include 9 different stages of the sugarcane growth and bare soil. Since we are interested in healthy vegetation, those areas with the possible occurrence of water stress and plant disease (according to the ground data collected by experts) were excluded. Out of the remaining digital photographs, 7 were used for supplying calibration equations and another 3 photographs were used for evaluation of these equations. To this we may add photographs taken from one leaf used for dust effect removal.

2 meters height above soil and/or plant, sun zenith and sun-camera azimuth were always kept constant while taking photographs. This to some extent reduces the uncertainties involved with the illumination 
conditions. The frame of camera was adjusted somehow that can include area between the centers of the two adjacent brooks 1.6 meters apart. The width of narrow brooks and ramps of sugarcanes were equal (Fig. 2).

The Phenological Dates (PDs) in units of DegreeDay (DD) for the 6 different stages of the sugarcane growth were extracted using ground data such as temperature-day collected routinely by the sugarcane industry experts ${ }^{[11]}$. This is shown in table (1). To use digital photographs in this study, some correction for the layer of dust on the leaves were found necessary. To implement this task the following simple method was applied.

A Method for Removing the Effect of Dust Off the Leaves: The sugarcane fields in the south-west of Iran are always subjected to the dusty winds and haze. To this we may add the dust due to the transportation in the nearby access roads. The layer of dust on the leaves renders correct evaluation of canopy indices using remote sensing techniques difficult.

To quantify the effects of dust on the RGB bands, 2 series of photos taken from sample leaves one before and the other after dust removal were prepared. These photos are different from those mentioned earlier. It is found that on the average the RGB bands of leaves photos show strong correlations with each other partly due to the presence of dust on the leaves and consequently needs some modification that will be explained as follow:

Due to the fact that during the dust removal, some displacement in the leaf position may occur, a region of interest (ROI) in each pairs of photographs (before and after dust removal) in the ENVI environment was selected in which a fix number of pixels (1200(row) by 1800 (column)) were contained. Then each of two pairs of photographs was pixel to pixel registered.

A sample of two photographs of one leaf with and without dust was prepared (Fig. 3). In the next stage, histograms of the photographs in three bands of RGB were produced. A sample histogram is shown in (Fig. 4). As can be seen in Fig. (4-left), the presence of dust on the leaf makes its histogram skewed toward the higher DN values in all three RGB bands. This skewness in the histogram is vanished when the leaf is cleaned (Fig. 4- right). To correct this anomaly which is due to the presence of soil dust on the leaves, the mean $\mathrm{DN}$ values in each of the three bands before and after dust removal were compared to each other. This was run for few leaves and on the average the difference

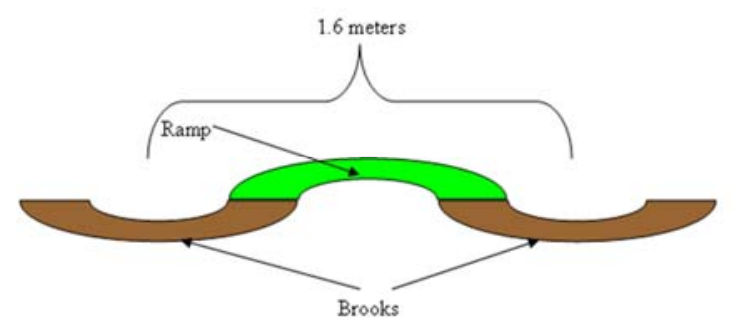

Fig. 2: Schematic diagram of the sugarcane cultivation geometry used in the frame of digital camera for each photograph

Table 1: Information regarding growing stages of sugarcane in the 6 selected digital photographs with the six different PDs

\begin{tabular}{lll}
\hline $\begin{array}{l}\text { Plant Age } \\
\text { (Days) }\end{array}$ & $\begin{array}{l}\text { Plant Physiological } \\
\text { Date (Degree-Day) }\end{array}$ & $\begin{array}{l}\text { Stage. } \\
\text { no }\end{array}$ \\
\hline 20 & 311 & 1 \\
56 & 1091 & 2 \\
112 & 2713 & 3 \\
183 & 3823 & 4 \\
305 & 4008 & 5 \\
356 & 4454 & 6 \\
\hline
\end{tabular}

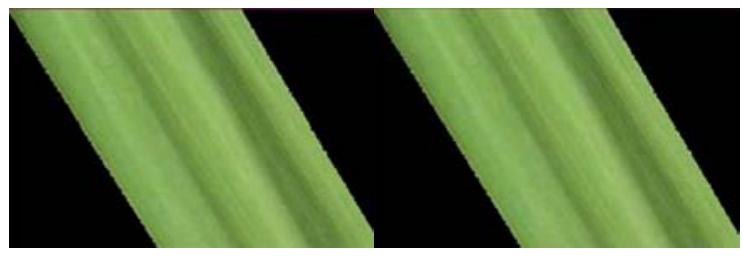

Fig 3: (left) dusty leaf, (right) dustless leaf

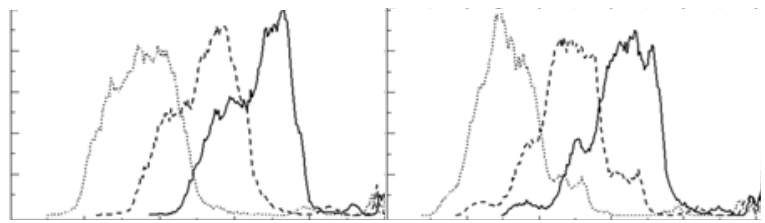

Fig. 4: Histogram of dusty leaf (a) and dustless leaf (b)

$$
\text { Red (-----) Green (.....), Blue (.....) }
$$

between these mean values (before and after dust removal) was found to be 13,8 and 9 for bands blue, green and red respectively. It means that the presence of soil dust on the leaves causes an increase in DN values in all three bands. Subtracting these DN values from each and individual pixels can vanish the skewness in the histograms and consequently make their distributions in all three bands closer to normal as can be seen in Fig. (4-right) for a sample leaf. Of course these discrepancies may vary from one field to the other but, it would be easy to handle whenever the need arises. 
In what follows, all photographs will be corrected for soil effect by subtracting 13, 8 and 9 from their pixel values in blue, green and red bands respectively.

To find a calibration equation for extracting information about plants phenological dates in units of Degree-Day (DD) using digital photographs, four methods were developed.

Method1- Rectangular Method (RM): In this method, the cultivation dates were extracted from crop tables. The threshold temperature $(\mathrm{Lt})$ for sugarcane was selected to be $16^{\circ} \mathrm{C}$ [based on the field reports]. Using minimum-maximum temperature from nearby weather station, one can calculate the DD values for those regions in the photographs.

\section{Method2- Maximum Likelihood Method (MLM):}

In this method, all photographs were classified in to two classes of soil and vegetation and their relevant percentages using Maximum Likelihood (ML) method. Also In this method a class is assigned to each pixel that has maximum possibility.

Method 3- Thresholding Method (TM): One of the main sources of errors especially in the wet soil is the presence of phytoplankton and micro organisms such as algae that photosynthesizes the light. Unfortunately this error was major in our work and thus due to the strong overlapping of RGB bands, it is found that the band ratio of green to red in the vegetated canopies containing chlorophyll and for all growing stages was always bigger than 1 which was suitable for our objective. However, this ratio for micro organisms containing chlorophylls was less than that of vegetation canopies. Thus by selecting appropriate regions on the ground and conducting different tests such as minimum-maximum reflectance in three RGB bands, the effect of this source of error was reduced.

Then using appropriate method of Thresholding (TM), the best threshold values was determined. As a result, the threshold for green vegetation was greater than 9 for the difference between green and red bands. This difference was less than 9 for algae covered surfaces.

Method 4- Hybrid Method (HM): This method is a combination of ML and TM methods i. e. using threshold technique for the first four growing stages and ML method for the other two stages.

\section{RESULTS AND DISCUSSION}

The results of running these 4 methods on the photographs are as follow:

Results of Rectangular Method (RM): To investigate a possible relationship between different bands of digital photographs and PD of the sugarcane, three bands of 7 photographs (one bare soil and 6 different regions with different cultivation dates) were used. The histograms of these photographs in three bands of blue, green and red are corrected for the dust effects and are shown in Figs (5) and (6). Of course this correction has not been done for the pure soil photograph.

As can be seen, three RGB bands have considerable overlapping but their distributions strongly differ for different stages of growth.

As the amount of vegetation cover increases, the red band takes the higher $\mathrm{DN}$ values while the green band takes the higher frequencies. Traditionally the relationship between the growing stage and PDs of plants is set through Leaf Area Index (LAI) and Excess Green $^{[12,13]}$.

In this work it is tried to find a relationship between different bands and PDs of the crops. Fig (7) shows variation of averaged DN values in three bands with the growing stages. As can be seen, green band shows the least and red band demonstrates the highest sensitivity to the growing stages. The blue band for the first three stages has low variations after which it drops to low value of DNs.

The rational response of red band to different stages of the plant growth makes this band suitable for estimation of the PDs of the plant. This is shown in Fig (8) along with a line and a polynomial fits to data. The fitted equations and their $\mathrm{R}^{2}$ values are shown in equations (1) and (2) below.

$$
\begin{aligned}
& \mathrm{DD}=-67.41 * \overline{\mathrm{DN}}_{\text {rd }}+9820.5, \mathrm{R} 2=0.9554 \\
& \mathrm{DD}=1.09 * \overline{\mathrm{DN}}_{\text {red }}^{2}-330.37 * \\
& \overline{\mathrm{DN}}_{\text {red }}+25291, \mathrm{R}^{2}=0.98
\end{aligned}
$$

Where DD is PD in Degree-Day and $\overline{\mathrm{DN}}_{\text {red }}$ is the averaged DN values in the red band. Equation (2) shows better stability and can be used for determination of PD of any plant using an ordinary digital camera. 


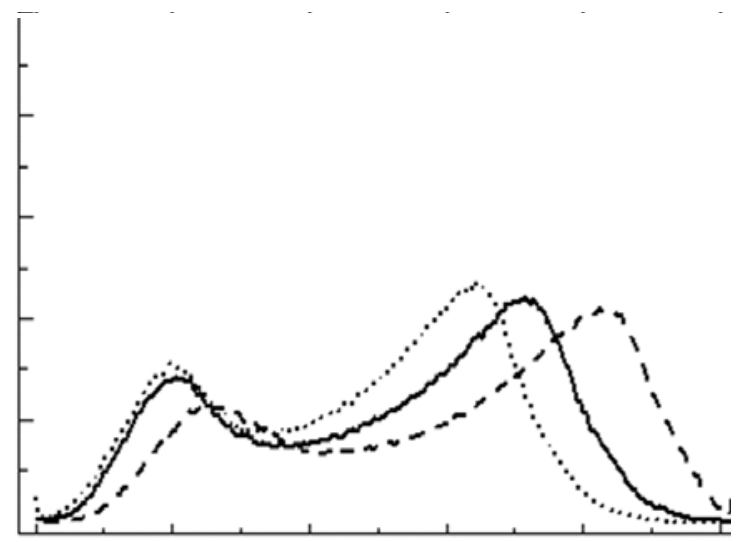

Fig. 5: Histogram of the soil scene with no vegetation cover. Red (solid) Green (dotted), Blue (dashed). Scales in abscissas (DN) 0 to 256 and in ordinate (frequency) 0 to 25000

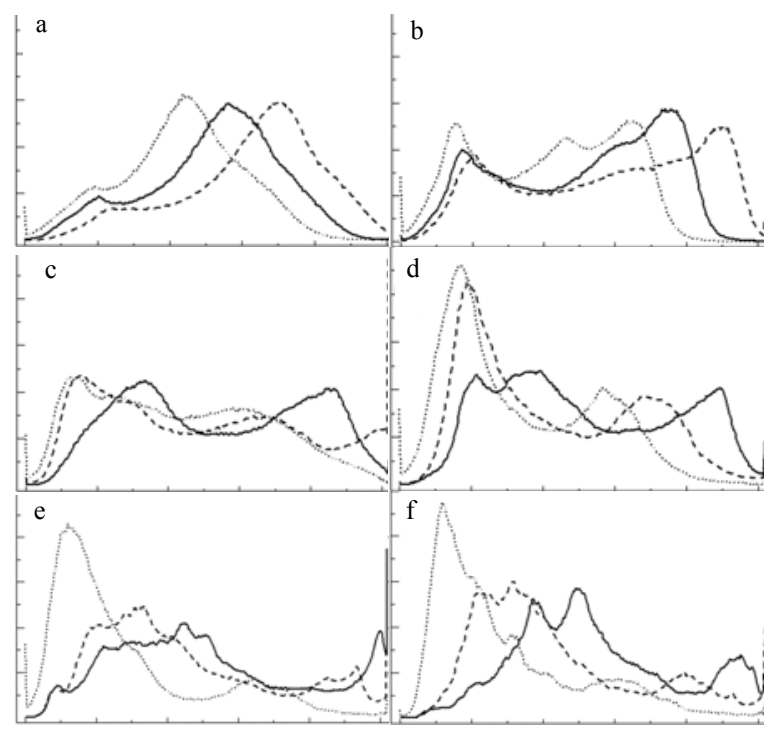

Fig. 6: Histograms of the $1^{\text {st }}$ to $6^{\text {th }}$ growing stages (a to b) with different DDs as follow: (a): 311, (b): 1091, (c): 2713, (d): 3823, (e): 4008, (f): 4456. Red (solid) Green (dotted), Blue (dashed), all figures scales in abscissas (DN) are 0 to 256 and in ordinates (frequency) 0 to 25000

\section{Results of Maximum Likelihood Method (MLM):}

By applying MLM method on the photos, the resulted classifications are shown in table (2).
Fig (9) Shows variation of PD with the vegetation covers percentage $\mathrm{P}$ where the fitting equations are presented in equation (3) and (4).

$$
\begin{aligned}
& \mathrm{DD}=36.933 * \mathrm{P}-270.37, \mathrm{R}^{2}=0.9667 \\
& \mathrm{DD}=0.2255 * \mathrm{P}^{2}+12.817 * \\
& \mathrm{P}+105.23, \mathrm{R}^{2}=0.9868
\end{aligned}
$$

here $\mathrm{P}$ is the vegetation cover percentage.

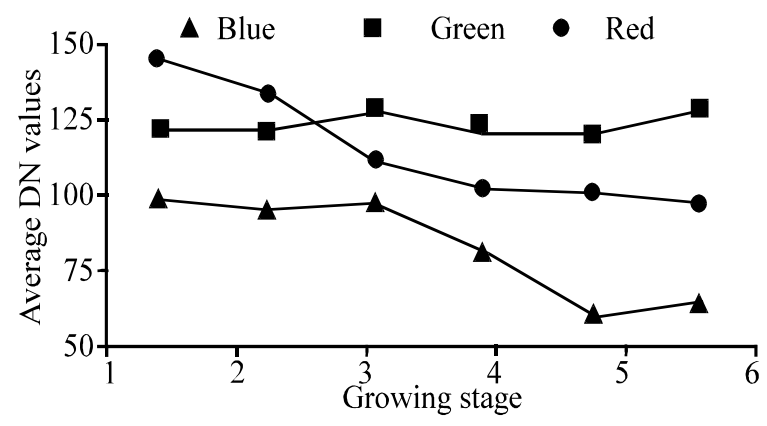

Fig. 7: Variation of the brightness values $(\mathrm{DN})$ of sugarcane in RGB bands in different growing stages

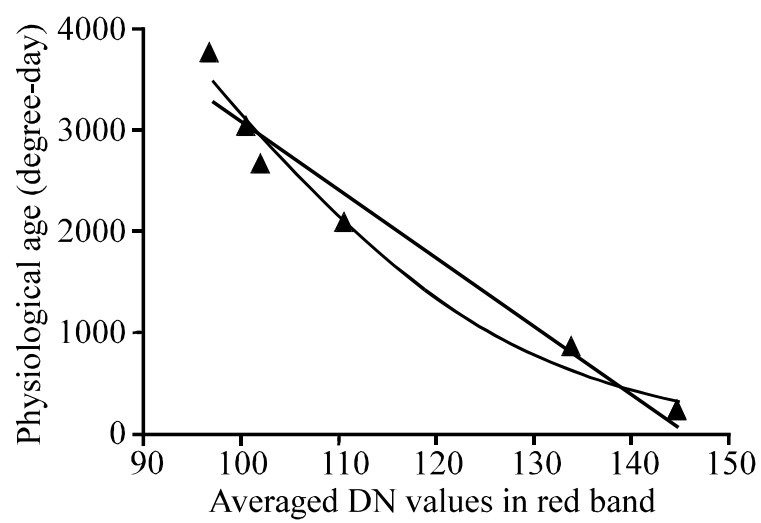

Fig. 8: Correlation between red band and plant PD

Table 2: Calculated vegetation cover percentage $(\mathrm{P})$ in 6 digital photographs using ML calassification method.

\begin{tabular}{lll}
\hline Photo No. & Physiological date (Degree-Day) & Vegetation cover (\%) \\
\hline 1 & 311 & 7.2 \\
2 & 1091 & 33.8 \\
3 & 2713 & 71.02 \\
4 & 3823 & 78.4 \\
5 & 4008 & 93.7 \\
6 & 4454 & 99.1 \\
\hline
\end{tabular}




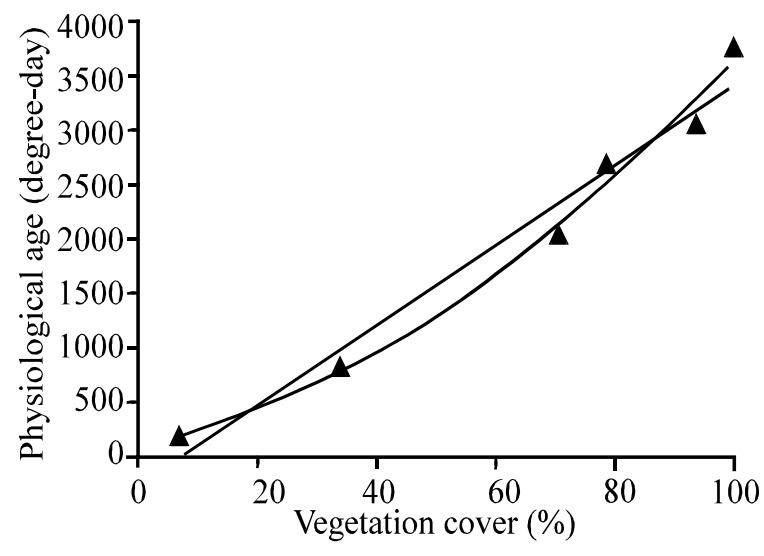

Fig. 9: Variation of PD with the vegetation cover percentage using ML calassification method

Results of Thresholding Method: Using PCI GEOMATICA 9.1 software and applying the threshold found in section 3.4 on Fig. (10-upper), Fig. (10-lower) was produced. The interesting point in this method was its ability in classification of the leaves shadow on the soil, in the soil class and the shadow of leaves on the leaves, in the vegetation class.

This is usually a serious source of error in remote sensing. Table (3) is the result of applying this threshold on 6 digital photographs of sugarcane while Fig. (11) is a plot of PD with respect to the P. The fitting equation for linear and quadratics polynomial is presented in equations (5) and (6).

$$
\begin{aligned}
& \mathrm{DD}=37.788 * \mathrm{P}-126.15, \mathrm{R}^{2}=0.9545 \\
& \mathrm{DD}=0.3465 * \mathrm{P}^{2}+5.074 * \\
& \mathrm{P}+246.39, \mathrm{R}^{2}=0.989
\end{aligned}
$$

Results of Hybrid Method: So far different approaches for achieving a rational relation between PD and $\mathrm{DN}$ values/ vegetation cover, have been studied. In ML method sources of errors and uncertainties such as phytoplankton and micro organisms that can synthesize the light especially in wet soils, can create some difficulties especially at the first three growing stages. On the other hand in the Thresholding method when separating soil from vegetation, we faced with some uncertainties in $5^{\text {th }}$ and $6^{\text {th }}$ stage of the plant growth, mostly due to the presence of senescent leaves and their distinction from soil. Then it would be wise to use a combination of these two methods i. e. using threshold technique for the first four growing stages and $\mathrm{ML}$ method for the other two stages.

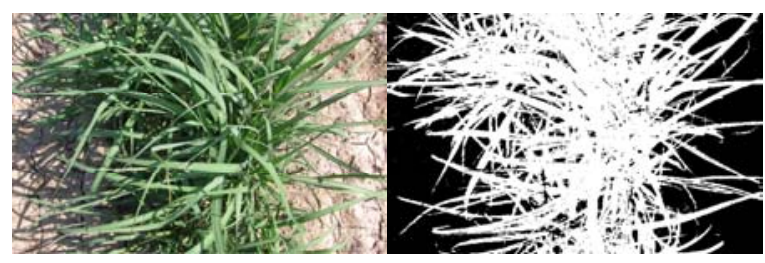

Fig. 10- Seperation of vegetation cover from algae using a threshold value for green minus red band.

\begin{tabular}{|c|c|c|}
\hline Photo No. & Physiological date (Degree-Day) & Vegetation cover $(\%)$ \\
\hline 1 & 311 & 3.1 \\
\hline 2 & 1091 & 28.23 \\
\hline 3 & 2713 & 69.22 \\
\hline 4 & 3823 & 78.12 \\
\hline 5 & 4008 & 80 \\
\hline 6 & 4454 & 93 \\
\hline
\end{tabular}

Table 3: The result of applying the threshold method on 6 digital photographs

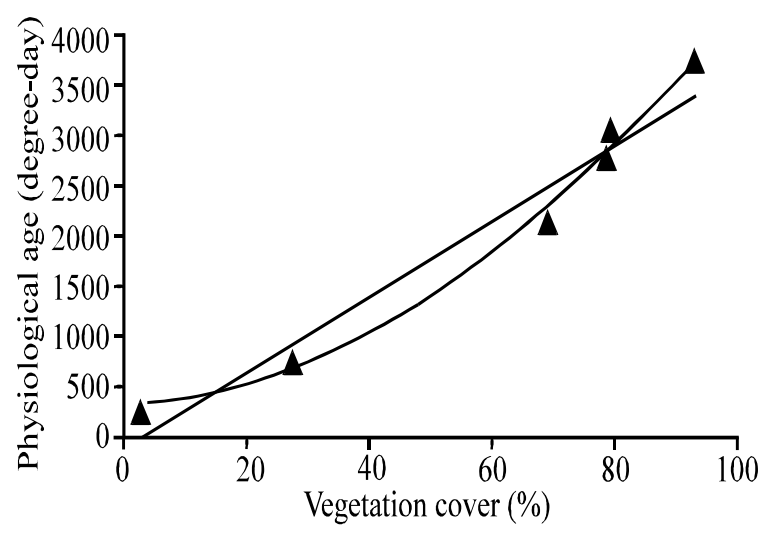

Fig. 11: Variation of PDs with the vegetation cover percentage $P$ applying thresholding method

Table 4: Results of PD in Hybrid Method

\begin{tabular}{lll}
\hline Photo No. & Physiological date (Degree-Day) & Vegetation cover (\%) \\
\hline 1 & 311 & 3.1 \\
2 & 1091 & 28.23 \\
3 & 2713 & 69.22 \\
4 & 3823 & 78.12 \\
5 & 4008 & 93.7 \\
6 & 4454 & 99.1 \\
\hline
\end{tabular}

It is reckoned that this hybrid method may increase confidence in evaluation of the plant PDs using vegetation cover percentages $P$. The results of hybrid method for the 6 growing stages are presented in table 
(4) and Fig. (12). The equations for the hybrid method are:

$$
\begin{aligned}
& \mathrm{DD}=34.91 * \mathrm{P}-74.28, \mathrm{R}^{2}=0.9704 \\
& \mathrm{DD}=0.1938 * \mathrm{P}^{2}+14.98 * \\
& \mathrm{P}+180.25, \mathrm{R}^{2}=0.987
\end{aligned}
$$

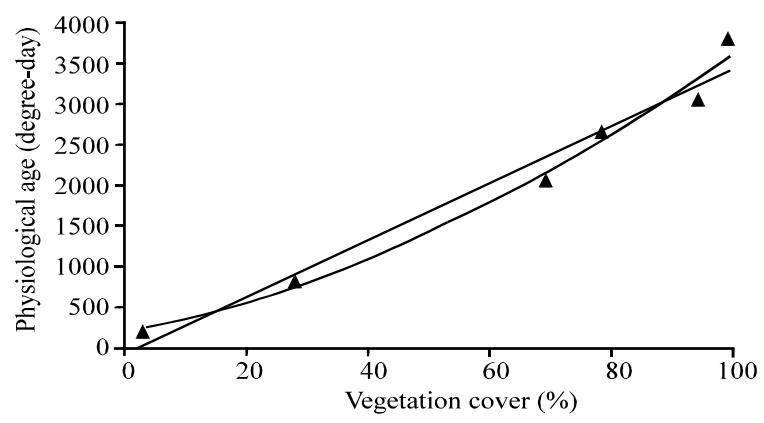

Fig. 12: Variation of PDs with the vegetation cover percentage using Hybrid Method

To test the ability of different methods, three photographs with known DDs and vegetation cover percentage $(\mathrm{P})$ were used. Using $\mathrm{DN}$ values and percentage cover extracted from each photograph and equations (3) to (8), DDs were calculated and compared with the true values. Correlation between the true values and prediction of four different methods, have been calculated and are presented in table (5) and in Fig. (13). Entering these predicted DDs and true values in the Wilcoxon signed-rank, the degree of significance level of each method's predicted values are evaluated and is presented in table (5). As can be seen $R^{2}$ of all methods are high enough but the HM method performs better. On the other hand significance level of the predicted data, shows weakness of the equation (8) in HM method (reading very high) and to some extent equation (5) compare to the other method's equations.

As a result equation (4) with $\mathrm{R}^{2}$ of 0.988 and equation (6) with $\mathrm{R}^{2}$ of 0.993 both with significance level of 0.827 are the best equations for estimation of phenological date using broadband digital cameras. This can clearly be seen in Fig. (13) where equation (8) is far away from true values although it has the best correlation with them. This to some extent is also true for equation (5) while for the rest of them the behavior of the predicted data and the true values were more or less the same.

\begin{tabular}{|c|c|c|c|c|c|c|c|}
\hline $\mathrm{P}(\%)$ & $\begin{array}{l}\text { DD } \\
\text { True values } \\
\text { Eq-8 }\end{array}$ & $\begin{array}{l}\mathrm{DD} \\
\text { Eq-3 }\end{array}$ & $\begin{array}{l}\text { DD } \\
\text { Eq-4 }\end{array}$ & $\begin{array}{l}\text { DD } \\
\text { Eq-5 }\end{array}$ & $\begin{array}{l}\text { DD } \\
\text { Eq-6 }\end{array}$ & $\begin{array}{l}\text { DD } \\
\text { Eq-7 }\end{array}$ & DD \\
\hline 30.3 & 853 & 849 & 701 & 1019 & 718 & 983 & 2878 \\
\hline 53 & 1336 & 1687 & 1418 & 1877 & 1489 & 1776 & 3245 \\
\hline 86.2 & 2974 & 2913 & 288 & 3131 & 3258 & 2935 & 4140 \\
\hline $\mathrm{R}^{2}$ & ----- & 0.962 & 0.9 & 0.962 & 0.993 & 0.962 & 0.996 \\
\hline Signif & ------ & 0.827 & 0.827 & 0.513 & 0.827 & 0.827 & 0.127 \\
\hline
\end{tabular}

Table 5: Comparison of the field data of DDs and the predicted DDs using different methods

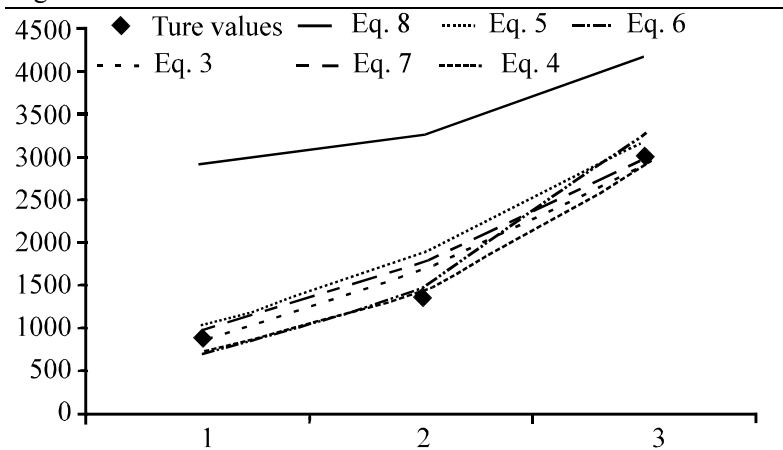

Fig. 13: A plot of the predicted DDs using Eq. (3) to (8) and true values (field data).

\section{CONCLUSION}

The objective of this work was to provide an equation for assessment of the quality of the phenological dates of the sugarcane in Degree-Day (DD). To do this, it was noticed that the effect of a layer of soil dust on the leaves can limit the capability of the procedure. A comparison of the histograms of the RGB bands in each leaf photo's before and after the dust removal showed that one can estimate the effect of the dust on the DN values in each of three RGB bands. This was be done by calculation of the difference between mean DN values in each band before and after dust removal. These differences were 9,8 and 13 for red, green and blue bands respectively. These values might be different in other fields and for other canopies in other times but, the calculation procedure would be the same.

To find an algorithm (an equation) with which we can quantify the plant foliage DDs as their outputs, 63 digital photographs were taken in three field campaigns on Sep29, 2006 through Oct1, 2006 from Amirkabir and Dea'bal-Khazaie sugarcane sites located in the south-west of Iran. These photographs included 9 different stages of the sugarcane growth and bare soil.

To find an algorithm for determination of plant phenological date four different methods were used. These were Rectangular Method (RM), Maximum Likelihood Method (MLM), Thresholding Method 
(TM) and Hybrid Method (HM). In each of these methods, a linear and a quadratic fitting curve was run to the plot of predicted vs. measured and it was found that MLM and TM methods performs better. To test the ability of these methods in the prediction of plants DDs, three photographs with known DDs and vegetation cover percentage were used. Entering these predicted DDs and true values in the Wilcoxon signed-rank test, the degree of significance level of the predicted value of each method was evaluated. As a result MLM with $\mathrm{R}^{2}$ of 0.987 and TM method with $\mathrm{R}^{2}$ of 0.989 both with significance level of 0.827 were the best methods for estimation of phenological date using broadband digital cameras.

\section{ACKNOWLEDGEMENTS}

This is to acknowledge the sincere and valuable cooperation of Amirkabir Sugarcane Industry managerial and administration in providing data and assisstance during the field campaigns.

\section{REFERENCES}

1. Mobasheri, M.R., Jokar, J., Ziaeian, P., Chahardoli, M. 2007b. On the Methods of Sugarcane Water Stress Detection Using Terra/ASTER Images. Journal of World Applied Sciences. Vol.2, No.6, pp. 619-627.

2. Nicholas C. Coops, Nicholas Goodwin, Christine Stone, and Neil Sims. 2006. Application of narrowband digital camera imagery to plantation canopy condition assessment. Can. J. Remote Sensing, Vol.32, No. 1, pp. 19-32.

3. Mobasheri, M. R. 2006. Producing ET map for Northern and Central Regions of Khuzestan Province Using 7ETM ${ }^{+}$Images. A Project Report to the Khuzestan Water and Electricity Organization.

4. Mobasheri, M.R., Rezaei, Y., Valadan Zoej, M.J. 2007a. A method in Extracting Vegetation Quality Parameters Using Hyperion Images, with Application to Precision Farming. AmericanEurasian Journal of Agricultural \& Environmental Sciences. Vol.2, No.5, pp. 476-483.
5. Berk A., Anderson G. P., Acharya P. K., Hoke M. L., Chetwynd J. H., Bernstein L. S., Shettle E. P., Matthew M. W., Adler-Golden S. M. 2003. MODTRAN4 Version 3 Revision 1 User's Manual. Air Force Research Laboratory, Space Vehicles Directoriate, Air Force Materiel Command, Hanscom AFB, MA 01731-3010, Hanscom.

6. Berk A., Anderson G. P., Bernstein L. S., Acharya, P. K., Dothe H., Matthew M. W., Adler-Golden S. M., Chetwynd J. H. J., Richtsmeier S. C., Pukall B., Allred C. L., Jeong L. S., Hoke M. L. a. 1999. MODTRAN4 Radiative Transfer Modeling for Atmospheric Correction. SPIE Proceeding on Optical Spectroscopic Techniques and Instrumentation for Atmospheric and Space Research III 3756, 348-353.

7. Song, C., Woodcock, C.E., Seto, K.C., Lenney, M.P., and Macomber, S.A. 2001. Classification and change detection using Landsat TM data: when and how to correction atmospheric effects. Remote Sensing of Environment, Vol. 75, pp. 230-244.

8. Liang S., Fang H., Chen M. 2001. Atmospheric Correction of Landsat ETM+ Land Surface Imagery-Part I: Methods IEEE Transactions On Geoscience And Remote Sensing, Vol. 39, No. 11.

9. Fraser, R. S., Ferrare, R. A., Kaufman, Y. J. and S. Mattoo. 1992. Algorithm for atmospheric corrections of aircraft and satellite imagery. Int. J. Remote Sensing, 13, 541-557.

10. Kaufman, Y. J. and D. Tanre'. 1998. Algorithm for remote sensing of aerosol from MODIS. MODIS Algorithm Theoretical Basis Document.

11. Aceituno P., 1979. Statistical formula to estimate heating or cooling degree-day. Agricultural Meteorology, $20:$ 227-232.

12. Vin, A., Gitelson, A. A., Rundquist, D. C., Keydan, G., Leavitt, B. and Schepers, J. 2004. Monitoring Maize (Zea mays L.) Phenology with Remote Sensing.. Agronomy Journal, Vol. 96.

13. Meyer, G.E., Hindman, T. and K. Lakshmi. 1998. Machine detection parameters for plant species identification. p. 327-335. In G.E. Meyer and J.A.DeShazer (ed.) Precision agriculture and biological quality. SPIE, Boston. 